\title{
Combined Iatrogenic Hyperinsulinemia and Excessive Weight Gain in Pregnancy
}

\author{
Hisham Arab* \\ Women and Fetal Health Program, Saudi Arabia
}

Submission: May 25, 2018 ; Published: June 06, 2018

"Corresponding author: Hisham Arab, Consultant Perinatologist, Women and Fetal Health Program, Dr Arab Medical Center, Jeddah, Saudi Arabia, Email: arab123@gmail.com

\begin{abstract}
The combined iatrogenic hyperinsulinemia resulting from prescribing large doses of insulin with an associated excessive maternal weight gain can easily be inflicted on pregnant patients with type 2 or gestational diabetes during the course of their management. Insulin helps control blood sugar, but insulin also causes insulin resistance and drives weight gain. Both elements may worsen the diabetic status and lead to unpleasant outcome. Current understanding of the pathophysiology and the introduction of new insulin made such complexity an avoidable and a treatable one once diagnosed.
\end{abstract}

Keywords: Insulin; Obesity; Gestational; Diabetes; Type 2; Hyperinsulinemia; Insulin-resistance; Hypoglycemia

Abbreviations: DM: Diabetes Mellitus; GDM: Gestational Diabetes Mellitus; BMI: Body Mass Index; IUFD: Intrauterine Fetal Death

\section{Introduction}

It has been estimated that $90 \%$ of diabetic pregnant women acquired diabetes during their pregnancy (Gestational Diabetes or GDM), while only $10 \%$ had pre-gestational diabetes that is equally divided in 5\% type I and 5\% type II Diabetes Mellitus (DM).

The primary goal of managing such patients is to achieve euglycemic control and avoid fetal and maternal complications. The basic management approach consists of the following triad: Diet, Exercise, and Insulin. These items should complement each other rather than taken individually. Normally, diet and exercise come first while insulin is used only when needed; regardless of the disease type. It is obvious that all type I and most of type II diabetics will require insulin therapy during pregnancy, however $5 \%$ only of GDM patients become in need of insulin [1].

It is not uncommon to come across a case of pregnant women taking more than 100 or 200 units of insulin per day to manage her diabetes in pregnancy and gained more than $20 \mathrm{~kg}$ by the time she entered the third trimester. This excessive weight gain is more than double the targeted weight gain recommended by the American Institute of Medicine (AIM) in 2009 (Table 1). In our opinion, this practice should be modified to avoid unnecessary high insulin doses with its untoward consequences. This review will illustrate the ill effect of this iatrogenic hyperinsulinemia in pregnancy.

Table 1: AIM 2009 Recommended weight gain in Pregnancy.

\begin{tabular}{|c|c|c|c|c|}
\hline $\begin{array}{l}\text { BMI at onset of } \\
\text { Pregnancy }\end{array}$ & $\begin{array}{l}\text { Underweight } \\
<18.5 \mathrm{Kg} / \mathrm{m}^{2}\end{array}$ & $\begin{array}{l}\text { Normal Weight } \\
18.5-24.9 \mathrm{Kg} / \mathrm{m}^{2}\end{array}$ & $\begin{array}{c}\text { Over Weight } \\
25.0-29.9 \mathrm{Kg} / \mathrm{m}^{2}\end{array}$ & $\begin{array}{c}\text { Obese } \\
>30.0 \mathrm{Kg} / \mathrm{m}^{2}\end{array}$ \\
\hline Targeted Weight Gain & $12-18 \mathrm{Kg}$ & $11-15 \mathrm{Kg}$ & $7-11 \mathrm{Kg}$ & $5-9 \mathrm{Kg}$ \\
\hline
\end{tabular}

\section{Too Much Insulin}

The natural response of any clinician to give insulin whenever the blood glucose is high seems to be partially sustained by a statement made by Oded Langer in 1998 describing insulin therapy in GDM patients by saying "It is appropriate to use the dose needed to achieve near normo-glycemic level without giving undue concern about giving too much insulin to the patient. The main concern should be blood glucose results rather than the dose of insulin" [2]. A statement like this has narrowed the vision 
of many doctors who started to chase glucose numbers with insulin and pay less attention to the total picture of a pregnant diabetic woman. Pregnant diabetics ended up receiving huge amount of daily insulin, which may compromise their wellbeing for the following 3 reasons:

1. Risk of Increased incidence of hypoglycemic attacks.

2. Risk of worsening the diabetic status of the patient due to:

a) Increased insulin resistance

b) Excessive weight gain

3. Risk of Dopamine Trap, and missing the benefit of Diet and Exercise as they are being underutilized.

\section{Hypoglycemia in Pregnancy}

The prevalence of severe hypoglycemia in patients treated with intensive insulin therapy during pregnancy is 19-44\%. Type I pregnant diabetics are most prone to have severe hypoglycemic episodes. It may occur up to 15 times during the course of a pregnancy. It is more often seen during the first trimester. Maternal and fetal adverse outcomes as a result of hypoglycemia in pregnancy are well known including maternal collapse and Intrauterine Fetal Death (IUFD). Several measures have been attempted to minimize such morbidity and one of them is to initiate patients on insulin analogues prior to pregnancy; which has shown a five times reduction in the rate of hypoglycemia [3].

\section{Insulin causes insulin resistance}

Patients with pancreatic tumors like insulinoma suffer from hyperinsulinemia along with increased insulin resistance; which is considered as a protective mechanism since high level of insulin may lead to steeply low blood sugar followed by seizure and death. Several human experimentations have shown that insulin resistance can be induced by insulin infusion of super high or physiologic doses $[4,5]$. Thus, high levels of insulin cause insulin resistance. The longer and higher the insulin levels, the higher the insulin resistance. Since type II DM, pregnancy itself, and GDM share the same feature of increased insulin resistance, then administering high doses of insulin to such patients will worsen their diabetes.

\section{Insulin drives weight gain}

When an intensive conventional insulin therapy for type II DM was applied on a group of patients over 6 months period, tight glycemic control was achieved without unacceptable hypoglycemia. However, this required large doses of exogenous insulin, an average of 100 units per day, to overcome the peripheral insulin resistance that lead to hyperinsulinemia with progressive weight gain. An average of $10 \mathrm{Kg}$ weight gain was noted on each individual [6].

Insulin is an anabolic hormone. As it increases the rate of glucose transport across the cell membrane, it increases the rate of glycolysis, glycogen synthesis, triglycerides incorporation into adipose tissue, and amino acid uptake by muscles. At the same time, it also decreases the rate of glycogen breakdown, lipolysis in adipose tissue, and protein degradation in muscle [7]. These processes lead to tissue build up and weight gain along with reduced caloric expenditure. Hence, massive insulin intake makes these women eat too much and exercise a little. Excessive weight gain in diabetic pregnancy, especially GDM or type II, is associated with adverse outcome such as macrosomia and perinatal morbidity and mortality [8]. Insulin cannot only cause generalized obesity, but it can also cause localized fat growth (lipohypertrophy) [9].

All studies have shown clearly, when controlled for congenital anomalies, the rate of pregnancy loss is higher in type 2 than type 1DM. Generally, the rate of IUFD in women with type I and type II diabetes were similar, at a rate of approximately $20 \%$, which is higher than in the general population. However, while the identified cause in type I was congenital anomalies in $75 \%$ of the cases, $75 \%$ of type II patients who suffered IUFD had a BMI>30 [10]. In addition to fetal loss maternal high BMI has been linked to higher incidence of certain congenital anomalies such as neural tube defect. Moreover, Body mass index has a greater impact on pregnancy outcomes than gestational hyperglycemia [11]. Maternal obesity (BMI>30 kg/m2) has been associated with double the risk of IUFD, chorioamnionitis, and birth asphyxia [12].

\section{Dopamine Trap}

It is quite mandatory to review religiously the daily activity and food intake of any pregnant diabetic taking insulin on every visit. Type 2 and GDM patients tend to be a bit overweight and most of them are lazy, not to mention being good eaters. This is a fact that can be overlooked easily in our clinics due to many reasons such as busy practice, staff inexperience, patients missing appointments, etc. When this happened, the doctor or the patient herself start to chase the increasing levels of glucose with more and more insulin and the patient keep putting on weight leading to what I call "Insulin-Eating Chase Syndrome" that simply creates a Dopamine Trap. It is well known that insulin leads to sugar craving through a Dopamine Trap cycle as shown in Figure 1; which further increases the weight gain trend. Hence, the cycle needs to be broken by doctor and patient awareness of the importance of taking corrective measures through dieting and daily exercise before increasing the dose of insulin. 


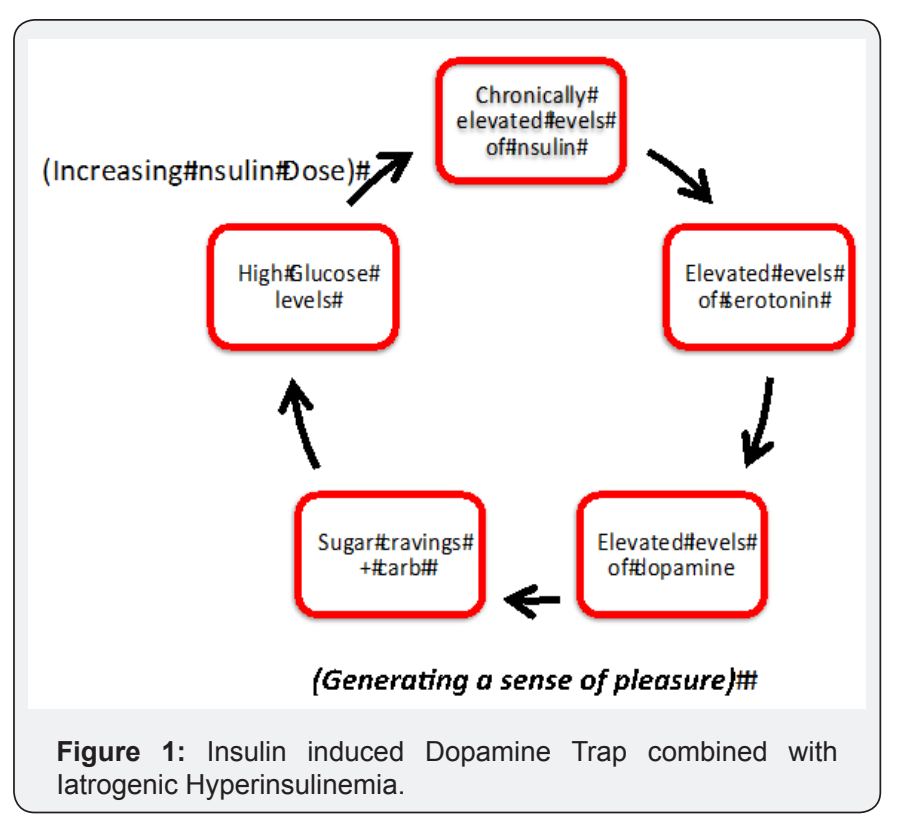

Moreover, this problem can be elicited easily in type 2 than type 1 diabetics because the former usually require more insulin than the latter during pregnancy. While there is no difference between the 2 types in the first trimester, insulin requirement increases by $10 \%$ in the second trimester and $20 \%$ in the third trimester for type 1, compared with $30 \%$ and $40 \%$ for type 2 , respectively.

Patients need to be told that exercise is not dangerous in pregnancy. On the contrary it helps reduce blood sugar levels, minimize the need for insulin, and many other things listed in Table 2. The mean glucose level in GDM patients who were on diet only was improved from $188 \mathrm{mg} / \mathrm{dl}$ to $106 \mathrm{mg} / \mathrm{dl}$ when exercise was added [13].

Table 2: Mechanisms of achieving euglycemia by exercise.

\begin{tabular}{|c|c|}
\hline 1 & Promotes cardiovascular fitness \\
\hline 2 & Increase peripheral insulin sensitivity \\
\hline 3 & Increase hepatic glucose uptake \\
\hline 4 & It is a good substitute for insulin in the management of GDM \\
\hline 5 & Exercising muscle takes up glucose in the absence of insulin \\
\hline
\end{tabular}

\section{Solving the Problem}

It is mandatory to understand that as long as maternal weight gain remains within the normal targeted range according to American Institute of Medicine (AIM) 2009 recommendations, then the intensified insulin dosage (of $>100 \mathrm{U} /$ day) is unlikely to cause harm except the hypoglycemia problem. However, once excessive weight gain is noticed, there are certain corrective measures that can be implemented to avoid adverse outcome. These measures can reduce the insulin dose by up to $50 \%$.

\section{Strategies to Limit Insulin Dose}

1. Insulin dose should be reduced immediately by $25 \%$; and then gradually according to her response to other interventions below.

2. Daily follow up with home glucose monitoring: allowing slightly high glucose levels at the beginning.

3. Weekly visits to emphasize the following actions:

a) Good dietary control with the help of a dietician who should participate actively to replace high glycemic index food with low glycemic index.

b) Regular exercise: at least 30 minutes walk after each meal.

c) Moderating stress level, getting enough sleep, and reducing body inflammation found to be helpful in reducing insulin resistance

4. Switch to Insulin Analogues; if not already on them:

a) Insulin pump

b) Using short or long acting analogues individually or mixed.

5. Occasionally, adjunctive treatment with the following may help limit the insulin dose:

a) Metformin

b) 2 other discouraged medications in pregnancy include

a) Pramlintide (Amylin producer)

b) Anorectic medications (anti-obesity drugs)

6. Recent recommendations suggest offering Metformin before Insulin to all GDM patients who are not controlled on diet and exercise over two weeks period [14].

\section{Conclusion}

Intensification of insulin doses for the treatment of diabetic patients during pregnancy usually causes excessive maternal weight gain, which has been correlated with adverse pregnancy outcome. Rigorous intervention with diet, exercise, life style, and some pharmaceutical modifications can optimize insulin therapy in pregnancy.

\section{References}

1. Arab H (1993) Gestational Diabetes: Regional Experience. Postgraduate Doctor 16(12): 196-202.

2. Langer O (1998) Maternal Glycemic Criteria for Insulin Therapy in Gestational Diabetes Mellitus. Diabetes Care 21(suppl 2): B91-B98.

3. Heller S, Peter D, Mersebach H, Vang T, Kaaja R, et al (2010) Hypoglycemia in Type 1 Diabetic Pregnancy. Diabetes Care 33(3): 473477.

4. Rizza RA (1985) Production of insulin resistance by hyperinsulinemia in man. Diabetologia 28(2): 70-75. 
5. Prato DS, Leonetti F, Simonson DC, Sheehan P, Matsuda M, et al. (1994) Effect of sustained physiologic hyperinsulinemia and hyperglycemia on insulin secretion and insulin sensitivity in man. Diabetologia 37(10): 1025-1035.

6. Henry R, Gumbiner B, Ditzler T, Wallace P, Lyon R, et al. (1993) Intensive conventional insulin therapy for type II diabetes. Metabolic effects during a 6-mo outpatient trial. Diabetes Care 16(1): 21-31.

7. Dimitriadis G, Mitrou P, Lambadiari V, Maratou E, Raptis SA, et al (2011) Insulin effects in muscle and adipose tissue. Diabetes Res Clin Pract 93(Suppl 1): S52-S59.

8. Jolly MC, Sebire NJ, Harris JP, Regan L, Robinson S, et al (2003) Risk factors for macrosomia and its clinical consequences: a study of 350,311 pregnancies. Eur J Obstet Gynecol Reprod Biol 111(1): 9-14

9. Holman RR, Kerensa IT, Farmer AJ, Davies MJ, Keenan JF, et al. (2007) Addition of biphasic, prandial or basal insulin to oral therapy in type 2 diabetes. N Engl J Med 357: 1716-1730.
10. Rasmussen SA, Chu SY, Kim SY, Schmid CH, Lau J, et al. (2008) Maternal obesity and risk of neural tube defects: a meta-analysis. Am J Obstet Gynecol 198(6): 611-619.

11. Ricart W, López J, Mozas J, Pericot A, Sancho MA, et al. (2005) Body mass index has a greater impact on pregnancy outcomes than gestational hyperglycaemia. Diabetologia 48(9): 1736-1742.

12. Cundy T, Greg G, Leonie N, Rose E, Paul MP, et al. (2007) Differing Causes of Pregnancy Loss in Type 1 and Type 2 Diabetes. Diabetes Care 30(10): 2603-2607.

13. Jovanovic (1999) Effect of Diet and Exercise in managing uncontrolled gestational diabetes. Diabetes 40(Suppl 2): 179-181.

14. NICE Guideline (NG3) (2015) Diabetes in Pregnancy: management from preconception to the postnatal period.

\section{Your next submission with Juniper Publishers will reach you the below assets}

- Quality Editorial service

- Swift Peer Review

- Reprints availability

- E-prints Service

- Manuscript Podcast for convenient understanding

- Global attainment for your research

- Manuscript accessibility in different formats

( Pdf, E-pub, Full Text, Audio)

- Unceasing customer service

Track the below URL for one-step submission https://juniperpublishers.com/online-submission.php 